University of Nebraska - Lincoln

DigitalCommons@University of Nebraska - Lincoln

Educational Psychology Papers and

Publications

Educational Psychology, Department of

January 1994

Homework: A Natural Means of Home-School Collaboration

Daniel E. Olympia

University of Utah

Susan M. Sheridan

University of Nebraska-Lincoln, ssheridan2@unl.edu

William Jenson

University of Utah

Follow this and additional works at: https://digitalcommons.unl.edu/edpsychpapers

Part of the Educational Psychology Commons

Olympia, Daniel E.; Sheridan, Susan M.; and Jenson, William, "Homework: A Natural Means of HomeSchool Collaboration" (1994). Educational Psychology Papers and Publications. 70.

https://digitalcommons.unl.edu/edpsychpapers/70

This Article is brought to you for free and open access by the Educational Psychology, Department of at DigitalCommons@University of Nebraska - Lincoln. It has been accepted for inclusion in Educational Psychology Papers and Publications by an authorized administrator of DigitalCommons@University of Nebraska - Lincoln. 
Published in School Psychology Quarterly, 9:1 (1994), pp. 60-80.

Copyright $\odot 1994$ American Psychological Association. Used by permission. "This article may not exactly replicate the final version published in the APA journal. It is not the copy of record." http://www.apa.org/journals/spq/

\title{
Homework: A Natural Means of Home-School Collaboration
}

\author{
Daniel E. Olympia, Susan M. Sheridan, and William Jenson \\ University of Utah
}

\begin{abstract}
The purpose of this article is to place homework in the framework of an emerging interest in the development of effective home-school partnerships. Specifically, review of the homework literature is provided with attention to parent-, teacher-, and child-mediated programs. Several homework programs that have received empirical support are described. Finally, the role of the school psychologist in supporting and coordinating complementary home-school homework programs is explored.
\end{abstract}

\section{REVIEW OF THE HOMEWORK LITERATURE}

Current concerns regarding the American educational system have led to increased interest in understanding various influences on school learning. These concerns are neither new nor confined to American schools. A Nation at Risk, the 1983 report of the National Commission on Excellence in Education, made educational improvement a national policy issue. An increasingly competitive and complex international environment has also created a renewed interest among educators and researchers in defining what constitutes effective educational practice. One variable that has been linked with increased student achievement is homework.

Homework is a valued educational tradition. Current prevalence estimates are provided by the National Assessment of Educational Progress (Anderson, 1986). Fully two thirds of 100,000 students in grades 4, 8, and 11 surveyed in 1984 reported that they spent some time on homework the previous evening. However, homework has not always enjoyed popular support among educators. Although there have been many critics of homework, educators and parents generally support its use. Even students see the inherent value of homework if it is reasonable, varied, and challenging (Anderson, 1986). The importance of homework was elucidated by a report of the Joint Commission on Mental Health of Children (1970), indicating that lack of academic productivity is a critical indicator for children "at risk" for school failure. Nevertheless, the National Commis- 
sion on Excellence in Education (1983) reported that the amount of homework assigned to American high school students had decreased (67\% of these students reported doing less than one hour of homework per night).

Early in the 20th century, many educators thought of homework as a means for disciplining children's minds (Brinks, 1937). In the 1940s, a trend toward less homework followed an emerging emphasis on problem-solving ability, as opposed to learning through drill and memorization. Home study was also perceived as an intrusion on students' time and private activities. Events in the 1950s reversed this trend with the advent of the space race. Educators once again viewed homework as a means for accelerating the pace of knowledge acquisition. By the mid-1960s, the pendulum reversed itself and parents and educators perceived homework as a sign of excessive pressure on students to achieve (Cooper, 1989). Currently there is a renewed interest in homework as a number of studies and reviews show a direct link between well-designed homework assignments and academic improvement (Keith, 1986; Miller \& Kelley, 1991; Otto, 1985; Paschal, Weinstein, \& Walberg, 1984; Walberg, Paschal, \& Weinstein, 1985).

\section{Definition of Homework}

Homework is a term that many have used but few have defined formally. Keith (1986) defines homework as that work which teachers typically assign for completion outside the normal class period. Cooper (1989) further refines this definition as " tasks which are assigned to students by school teachers ... meant to be carried out during non-school hours," and adds that students can have "options of completing homework during other times, such as study halls, library times or during subsequent classes" (p. 7). While students may partially complete homework in school, it is assumed that most assigned work is completed at home. Excluded are practices such as in-school guided study, lessons presented via home video, audiocassette or TV, and extracurricular activities such as team activities or debate clubs (Cooper, 1989).

Definitions of homework also have incorporated more detailed descriptions and classification of specific practices. Lee and Pruitt (1979) characterize homework to include practice (repetition and drill), preparation (advance groundwork), extension (application of learned skills to a new task), and creative (original use of learned skills) work assignments. Clearly, homework can fulfill several purposes. Likewise, various benefits to students, parents and teachers have been described. For example, practice homework increases speed and mastery of skills. Participation of students in homework increases involvement in the learning task. Likewise, personal development of students is enhanced by building student responsibility, perseverance, time management and self confidence. Homework can enhance parent-child communication on the importance of schoolwork and learning. Homework also fulfills policy directives from administrators who require a prescribed amount of homework per week. Homework serves a public relations purpose by informing parents of what happens in class. Homework has also been used as punishment to remind students of requirements for behavior or 
class assignments (Epstein, 1988a).

For purposes of this article, we define homework as academic work assigned in school that is designed to extend the practice of academic skills into other environments during nonschool hours. This definition stresses the importance of homework as a means of programming for academic skill generalization (Stokes \& Baer, 1977). In other words, the natural extension of schoolwork from academic to nonacademic settings (i.e., generalization of academic skills across settings) is an important feature of homework. However, as indicated by Rutherford and Nelson (1988), less than 2\% of 5,300 articles reviewed addressed maintenance and generalization of educational treatment effects.

\section{Homework and Achievement}

Recent studies focusing on the relationship of homework to achievement has helped to spark a renewed interest in homework. In general, time spent on homework has important and positive effects on achievement, whether measured by grades or by test scores (Anderson, 1986; Cooper, 1989; Fredrick \& Walberg, 1980; Keith, 1982; Rutter, Maughn, Mortimore, Ouston \& Smith, 1979). Achievement gains have been associated with homework that (a) is graded or commented upon, (b) contains positive comments, (c) is followed by consequences versus no consequences, and (d) is reviewed or checked by parents (Keith, 1987). Long-term and cumulative academic gains have been associated with an efficient homework program for handicapped, gifted, at-risk, and low achieving students (Chadwick \&Day, 1971; Fredrick \& Walberg, 1980; Harris \& Sherman, 1974; Paschal et al., 1984; Rousseau, Poulson, \& Salzberg, 1984). Homework may also have compensatory effects; that is, less able students can compensate for lower ability through increased home study (Polachek, Kniesner, \& Harwood, 1978).

Homework has been identified as one of the most important practices for establishing a successful academic environment (Epstein, 1988a). Coleman, Hoffer, and Kilgore (1981) found that homework and discipline were two essential features of private schools that made them more successful learning environments than public schools. Schools in which teachers gave frequent and large homework assignments produced better student outcomes than did schools in which teachers assigned little homework (Rutter et al., 1979).

Research regarding the effectiveness of homework has led to equivocal results. Several reviews have associated homework with higher achievement for a variety of students, school subject matter, grade levels, and learning environments (Austin, 1979; Goldstein, 1960; Keith, 1986,1987; Marshall, 1983; Paschal et al., 1984; Strang, 1975). However, other investigations have cited negative, or inconclusive evidence for homework's effectiveness (Friesen, 1979; Harding, 1979; Knorr, 1981; La Conte, 1981; Strang, 1968). Strang (1968) states that available research shows "systematically assigned homework contributes to academic achievement to a variable degree for able learners, to some extent for average students and to a more marked degree for the slow learner" (p. 29). La Conte (1981) concluded that homework improves mathematics performance 
under certain circumstances, particularly at the high school level. However, he found no conclusive evidence for homework's general effectiveness with other age groups or subjects and concluded that homework may be inappropriate and counterproductive for young children. The question of homework's suitability for elementary students has been raised more recently by Cooper (1989), Epstein (1988b), and others.

In recent reviews of homework research, Keith $(1986,1987)$ concluded homework enhances achievement from elementary through high school grades. This effect appears across a variety of subject areas and student ability levels. Other positive effects are also attributed to homework, including motivational and concentration skills that generalize to nonschool settings (Keith, 1986). Cooper (1989) provided the most current review of the literature on the relationship of homework to achievement and related variables. In this review, homework research was evaluated on three dimensions: homework versus no-treatment, homework versus in-class supervised study, and time spent on home-work assignments. In general, positive effects were found across all three types of studies, with the largest effect attributed to time spent on homework. Specifically, the average student spending more time on homework scored .39 standard deviations higher on academic outcomes than the average student reporting less time spent on homework. The smallest effect was found in comparisons of homework with in-class supervised study, where only .09 standard deviations separated the comparison studies (Cooper, 1989).

One moderator of homework's effect that appears remarkably consistent across the research is grade level. Upper level elementary students show the smallest effect size for homework, while high school students show the largest effect. According to Cooper, the "average student doing homework over a10-week period would be expected to outscore $52 \%$ of no-homework students if the class is in the upper elementary grades, about $60 \%$ in the junior high grades and $69 \%$ in the high school grades" (p. 164). Homework's positive effects on achievement also occur irrespective of gender and intelligence level (Cooper, 1989). It should be noted that several concerns regarding the internal validity of homework research have been raised, which warrants against making broad inferences about homework based on the available research (Cooper, 1989).

A common thread present through much of the literature concerns the limited amount of sound experimental research on homework. Research assessing the effectiveness of various types of homework on achievement outcomes is not welldeveloped and is often confounded by subject matter and curricular intent issues (Foyle, 1984; Foyle \& Bailey, 1988). This may contribute to contradictory findings and inconsistent evidence for homework's effectiveness (Cooper, 1989).

\section{Homework Compliance}

While existing research generally supports the relationship of homework to school achievement, homework compliance has been a continuing source of concern for parents and educators alike (Lieberman, 1983; Maertens \& Johnson, 
1972). Homework will not fulfill any purposes if students do not complete assignments (Keith, 1986). Children often exhibit poor motivation and avoidance of academic tasks outside of the school setting, and poor study habits and poor academic performance are a source of continual conflict in many families (Anesko \& O'Leary, 1982). Study problems and homework compliance difficulties often begin during the elementary school years when homework assignments are first required by teachers. Presently, research is limited and provides little data on integrated programs designed to secure homework compliance and accuracy.

Since homework problems are prevalent in the general population (Anesko, Schoiock, Ramirez, \& Levine, 1987), preventive and remedial interventions would be very useful (Miller \& Kelley, 1991). Strategies to increase compliance can be mediated by parents, teachers, or students themselves. By focusing on homework as a generalization strategy, several interventions seem particularly suited to the problem of homework compliance. Stokes and Baer (1977) describe generalization as the "occurrence of relevant behavior under different, non-training conditions (across subjects, settings, people, time) without the scheduling of the same events in those conditions as had been scheduled in the training conditions" (p. 350). They suggest that the most dependable of generalization programming mechanisms is the of use of natural contingencies available in the environment (Stokes \& Baer, 1977). Homework completion may provide the student with an introduction to the natural reinforcers inherent in school achievement (e.g., grades or positive comments from teachers or parents). Unfortunately, in many instances there is no natural reinforcement operating to produce and maintain academic performance. In these situations it may be necessary to restructure the environment by providing parental or teacher training and support. Several areas of applied behavioral technology have treated academic problems successfully through contingency contracting, home notes, and other prompts.

Authors have advocated using indiscriminable contingencies and intermittent schedules of reinforcement to promote generalization (Stokes \& Baer, 1977; Stokes \& Osnes, 1986). Unpredictable contingencies may be especially useful with the type of independent, unsupervised responding that homework requires. Another generalization approach suggests that sufficiently similar stimulus components occurring in both the trained and untrained settings will promote behaviors from setting to setting. A common stimulus approach to homework would incorporate physical stimuli that are believed to be prominent or functional in the school environment (e.g., independent work space, a nondistracting environment). We now review homework research that has utilized these and other model interventions with parents, teachers, and students as the primary targets.

\section{TARGETS OF INTERVENTION}

\section{Parent Training}

The popularity of parent training reflects an increasing movement toward the use of parents as therapists or behavior change agents for a variety of problem 
behaviors (Dangel \& Polster, 1984). Psychologists have developed programs to help parents manage fairly severe child behaviors, including acting out, temper tantrums, hyperactivity, school truancy, and other severe forms of child problem behaviors (Tavormina, 1980). Behavioral interventions that provide parents with specific skills in response to a precisely defined target problem are particularly effective.

Reviews of the current literature indicate a relatively small body of research dealing with parent-child conflict over homework. Parent training techniques and materials have been described in some limited reports to improve students' homework performance. However, most of these reports provide merely an outline for training parents on homework problems, with insufficient empirical documentation of their effectiveness.

Kuhlman (1973) provided brief parent training that focused on the completion of mathematics homework and tutoring for seventh- and eighth-grade students deficient in math skills. With the use of several behavioral interventions (e.g., contracting, reinforcement contingencies), junior high school students demonstrated increased academic behavior at home, improvements in self concept, and more motivation for academic tasks. Anesko and O'Leary (1982) evaluated the effectiveness of parent training to remediate homework problems based on behavioral management principles with a population of normal elementary aged children. Group meetings were supplemented by readings and activities described in a parent manual. The treatment proved to be an effective package for parents experiencing problems with their children's homework compliance. Several commercial materials are available for parent training related to homework problems. Anesko and Levine (1987) developed Winning the Homework War, which contains useful materials for assessment and treatment of homework difficulties. The homework checklist included in this program is well-researched and many of the techniques are based on best practices (e.g., daily homework record, setting appropriate goals, self-instructional training). However, it may be difficult for some parents to read and follow through on instructions provided in the training manual. These materials may be more helpful to the school psychologist who consults with parents and is in a position to interpret for parents various features of the program.

Homework Without Tears is a parent training package marketed by Canter and Associates (Canter \& Hausner, 1987). This series includes a Homework Organizer for the student and a manual for the teacher. The program is similar to others with an emphasis on time scheduling, incentives, communication techniques, and common sense tips. The materials are easy to read and include several illustrations and humorous cartoons. An added advantage is that these materials can be implemented in conjunction with Assertive Discipline classroom techniques used by many teachers. However, little information is available on the overall effectiveness of the program.

Homework Helpers (Kuepper, 1987) and Mindmovers: Creative Homework Assignments Grades 3-12 (Hart \& Rechif, 1986) are two publications directed to- 
ward parents and teachers. These programs provide many examples of homework contracts, various types of homework assignments, study skill sheets, and other aids to facilitate homework completion. While these materials are easily adapted for classroom use, there is no systematic evaluation of their effectiveness.

The Do it Yourself Homework Manual: A Sanity Saver for Parents was developed at the University of Utah (Olympia, Jenson, \& Neville, 1990) to support a group-based parent training program with an emphasis on parents designing their individual programs. While materials were primarily developed for late elementary and beginning junior high school students, some aspects of the program are suitable for late junior and high school students. The basic design centers around a five-week group training sequence led by a school psychologist, although individual applications are also possible. Training is based on a behavioral model which provides opportunities for parents to identify specific areas of concern, practice appropriate interventions specific to identified problem areas, and evaluate their efforts in a small group format. General issues addressed in the "Do it Yourself" program include (a) assessing homework problem areas; (b) managing environmental variables such as the setting, materials, and time for homework; (c) implementing motivational programs; (d) establishing appropriate contacts with the school; and (e) setting up a tutoring program.

Practice "homework assignments" are given to parents at various stages of the program. For example, in the second session, parents are asked to establish contact with the teacher, implement a home note system, and address homework environment issues (e.g., where and when homework can be completed). Parents are also trained in specific motivational strategies to enhance the effectiveness of their program. Examples of several motivational systems are presented during this session.

The "Do It Yourself program is currently undergoing field review and pilot testing with several groups of parents in selected school districts. Preliminary data suggest that parents are very favorable toward the program. Parents and students have expressed particularly positive reactions to the assessment and motivational components. Parents further report that the procedures are easy to understand and incorporate into the natural home environment.

A major drawback associated with parent training homework programs is the inability of many parents to maintain regular participation. Consequently, treatment "packages" may be implemented incorrectly or discontinued after a brief trial. This highlights the need for a consultant to monitor implementation of programs to ensure parental compliance and follow through. Furthermore, more direct school psychologist involvement may be necessary (e.g., direct training, parent-teacher consultation) to the extent that individual parents have difficulty comprehending programs or implementing them with integrity.

\section{Teacher-Based Interventions}

Motivational approaches have been shown to improve homework completion in residential and school-based research projects (Harris \& Sherman, 1974; 
Phillips, 1968). A common aspect of these programs is the role of the classroom teacher in treatment implementation. Teacher-based interventions include methods of individual and group reinforcement, response cost, and home notes.

Contingent Reinforcement. Individual positive reinforcement programs have been shown to generate and maintain increased rates of homework completion. For example, Malyn (1985) used a "spinner" and magic ink system to increase homework compliance in a residential setting for students with behavior disorders. Teachers checked each student's arithmetic homework at the beginning of the school day. If the student had completed the assignment and $80 \%$ of the problems were correct, the student could touch a developing pen to one of 100 reinforcement boxes on a poster board. If the pen revealed a randomly placed reinforcement star, the student was allowed a "spin" on a reinforcement wheel. Using this schedule of variable reinforcement, Malyn (1985) demonstrated significant initial increases and maintenance effects in homework performance with this population of resistant students.

Research on effective teaching practice has demonstrated the positive effects of providing response-contingent feedback on both individual and group performance (Elliott \& Shapiro, 1990). Public posting of academic performance has produced improvements in student performance and increased math and composition skills with both elementary and secondary level students (Van Houten, Hill \& Parsons, 1975; Van Houten \& Lai Fatt, 1981; Van Houten \&Thompson, 1976). In some cases, providing students with simple feedback alone has been sufficient to alter academic deficits (Elliott \& Shapiro, 1990).

Group contingencies also have been employed in several homework studies. Group contingencies can be characterized in one of three ways: (a) dependent, where group attainment of a reward depends on the performance of a "target" student who is expected to meet a selected criterion; (b) independent, where each student's participation in a group reward is dependent on his or her own performance; and (c) interdependent, where group attainment of a reward is dependent on the performance of the group as a whole against a preselected criterion (Litlow \& Pumroy, 1975).

There are many advantages to using group contingencies for increasing homework compliance. Teacher time required to chart behaviors and distribute rewards can be reduced significantly, and peers can act as behavior change agents (Elliott \& Shapiro, 1990; Pigott, Fantuzzo, Heggie, \& Clement, 1984). Several disadvantages of group contingencies also have been identified. For example, students can be affected by the poor performance of a single student, groups may lose motivation once they perceive that they have lost reinforcement for a specific day (Crouch, Gresham \& Wright, 1985), and students may experience negative peer pressure effects (Axelrod, 1973; Shores, Apolloni, \& Norman, 1976).

Response Cost Systems. Response cost programs penalizing students for lack of homework completion have been described in the literature. While some studies have shown that earning free time can improve academic performance (Johnston \& McLaughlin, 1982), the loss of free time after school also has been sug- 
gested as a negative reinforcer. Lieberman (1983) outlined a system in which students earned the right to do homework at home. Teachers allowed students to take their assigned work home for completion, but students who repeatedly failed to return homework were placed on probation for five days. During these five consecutive days, students were required to report to the "homework room" after school to complete their assignments. A follow-up period then ensued in which homework completion alternated between home and school for five days. Lack of homework completion resulted in an additional five days of in-school probation. This system appears promising, given close collaboration between parents and teachers. However, no empirical evidence has been provided regarding its effectiveness (Lieberman, 1983).

Home Notes. Teachers have used home notes effectively to improve homework completion (Dougherty \& Dougherty, 1977; Kelley, 1990; Lordeman \& Winett, 1980). Home notes are completed by the teacher and include items such as assigned academic tasks, grades given on assignments and tests, homework items that have been turned in, and those that have been missed. A major strength of home notes is that they build a communication link between parents and teachers. In addition, parents can enhance the effectiveness of home notes by setting up a home-based incentive system that provides contingencies based on performance reported in the note. Lordeman and Winett (1980) found that junior high school students increased overall homework submission by $20 \%$ using a home note system. The note simply (1) informed the parent of the rate of submission of homework reading assignments, and (2) provided a qualitative feedback statement about their child's work.

\section{Student-Mediated Programs}

Although the effectiveness of using external agents (e.g., parents, teachers) to carry out behavioral change programs has been well-documented, there are also several drawbacks. These include loss of actual teaching time to time spent managing behaviors, difficulties in observing and providing consequences to behavior consistently across subjects and settings, lack of generalization of skills, and the association of parents and teachers with the administration of negative contingencies (Kazdin, 1975). Behavioral techniques which minimize the role of the external agent and assign greater control of contingencies to individuals and groups of students offer a means of overcoming these disadvantages.

Cooperative Learning. Cooperative learning is a recent innovation described in the academic management literature that uses small groups of mixed ability students who learn or complete a task together (Elliott \& Shapiro, 1990; Slavin, 1980). Cooperative learning structures the learning environment by providing for mutual goals, division of labor, role interdependence, and group rewards. Applications of cooperative learning share the basic concept of a cooperative goal structure.

While the rationale for cooperative learning emphasizes social and emotional growth issues, significant effects on academic achievement, cognitive growth, 
and motivation have been forthcoming. Several reviews have concluded that favorable academic effects are evident across settings and students at all grade levels (Nastasi \& Clements, 1991; Sharan, 1980; Slavin, 1983). Cognitive and academic benefits have been reported for students from early elementary through college levels, from different cultural backgrounds, and across a wide range of ability levels (Nastasi \& Clements, 1991). Additionally, cooperative learning strategies have produced significant gains across a wide range of content areas, including mathematics and other core subjects (Johnson \& Johnson, 1985; Slavin, 1985). The most successful cooperative learning methods for increasing student achievement (a) use group scores (comprised of individual achievement scores) to provide feedback to students, and (b) provide each member with a unique task for which he or she could be held accountable (Slavin, 1983). However, the effectiveness of classroom-based strategies that employ cooperative, peer-mediated procedures to support homework assignment completion has not been researched.

Self-Management. Recent developments in cognitive-behavioral science have provided additional rationale for increased client participation in educational interventions. Self-management encompasses several techniques that can be included under two general headings: verbally mediated strategies, which involve overt and covert rehearsal, and contingency management procedures. Collectively, these include self-instruction, self-assessment (i.e., monitoring, evaluating, and recording), self-determination of reinforcers, and self-administration of reinforcers (Bornstein \& Quevillon, 1976). A central aspect of self-management requires that control of the contingency rests with the individual.

Descriptions of intervention procedures based on self-management can be found in the literature (Karoly \& Kanfer, 1982; Meichenbaum \& Goodman, 1971; Roberts \& Dick, 1982; Smith, Young, Nelson, \& West, 1992; Shapiro, 1986). Horner (1987) developed a four-stage, problem solving model used with parents to improve homework performance (i.e., establish a notebook system; design a daily schedule; use verbal problem solving; and fade out the prompts). Unfortunately, no evaluation data of these procedures are provided. Fish and Mendola (1986) used similar verbal self-instructional techniques with three children to improve homework completion in mathematics, reading, and language arts. These techniques were effective at producing marked increases in homework completion across students, with excellent follow-up results (i.e., approximate average increase of $40 \%$ ). Although data on homework completion were provided, accuracy data for the assignments were not presented.

The combination of self-management with group-oriented contingencies has been particularly effective at improving on-task behavior in academic settings (Pigott et al., 1984; Wolfe, Fantuzzo, \& Wolter, 1984). Within this configuration, researchers have trained children to prompt, monitor, evaluate, and reinforce their own academic behavior. Group-oriented contingencies are used to take advantage of peer influences by involving more than one student in a contingency management program. Wolfe et al. (1984) used a student-controlled group con- 
tingency to increase arithmetic performance of grade school children in a clinic setting. Roles of "Coach," "Scorekeeper," "Manager," and "Referee" were assigned to students. Each role corresponded to a specific self-management function. Students performed these roles in the context of regular math drill sessions. Using a single subject design, increases in arithmetic performance across four subjects were found. Interestingly, nontreated disruptive behavior also decreased significantly. A similar study was completed by Pigott et al. (1984) using fifthgrade underachieving students in a natural school setting. Results show that the intervention was effective, but students did not maintain improvements in performance on a six week follow-up.

The "Homework Teams" homework program (Olympia, Andrews, Valum, \& Jenson, 1991) is a peer-mediated, student driven homework program that takes advantage of positive peer influences to reinforce homework proficiency. Several options are provided which allow teachers to tailor the basic model to specific circumstances, student characteristics, and problem situations. This program provides students with daily feedback and maximizes opportunities for reinforcement of success. Since homework that conforms to proven teaching methods shows the greatest relationship to achievement gains, the "Homework Teams" teacher manual contains a review of good homework practices, and presents several key aspects of effective homework practices.

Outcomes of the program have been reported for two distinct populations: normal but underachieving sixth grade students and self-contained, behavioral disordered elementary students (Olympia, Jenson, \& Sheridan, 1992). Results indicate that students are able to implement the procedures reliably and are motivated to complete homework accurately. Significant gains were apparent on curriculumbased measures and standardized tests of mathematics achievement as a function of the program. Additionally, parents reported fewer homework avoidance tendencies and increased motivation to complete work independently and accurately.

Evaluation of self-management outcomes indicates that these procedures foster independent growth and development in children's academic and social skills (Fish \& Mendola, 1986). The use of self-management procedures also promotes behavioral generalization across time and settings (Holman \& Baer, 1979). The natural progression of homework from supervised study to independent practice appears uniquely suited to self-management interventions.

Shortcomings in the self-management literature are also clear. Self-management interventions often have been poorly defined and the specific terminology has become idiosyncratic and misapplied. Clear and specific guidelines outlining the steps by which to train self-management skills to elementary aged children are lacking, and there is considerable variability in true adherence to the procedures (Fantuzzo, Rohrbeck, \& Azar, 1986). Nevertheless, developments in the use of peer tutors and cooperative learning approaches show considerable promise for remediating many academic problems, including homework compliance (Cooper, 1989). 


\section{Interactive Programs}

Above we have outlined parent-, teacher-, and student-mediated approaches to homework. Some interesting and promising homework materials have been developed by Joyce Epstein and her colleagues at the Center on Families, Communities, Schools, and Children's Learning in Baltimore (Epstein, Jackson,\& Salinas, 1992; Epstein \& Salinas, 1991, 1992). The Teachers Involve Parents in Schoolwork (TIPS) interactive homework process was developed to allow teachers to help all families stay informed and involved in their children's learning activities at home, and help students complete homework to promote school success.

With the TIPS process, homework is conceptualized as a three-way partnership involving students, families, and teachers. Prototype materials are available for math (grades K-5), science (grade 3), and language arts, science, and health (middle grades). The materials feature homework assignments that require students to talk to someone at home about things they are learning at school, and provide a structured means for parents to provide written feedback to teachers. Thus, TIPS homework is primarily the students' responsibility, requires interaction between students and their parents, and enables students to share with parents things they are learning at school. Among the major goals of the TIPS process appear to be the involvement of all parents in their children's schoolwork, reciprocal home-school communication, and the development of challenging and engaging homework assignments requiring higher level thinking skills and interactions with family members. According to Epstein and Salinas (1992), "TIPS homework ... is designed specifically to keep students and their families talking about schoolwork at home" (p. 2).

\section{Quantitative and Qualitative Variables Contributing to Homework's Effectiveness}

Inherent in the assignment of homework tasks, there seems to be an implicit belief that such activities improve student learning, boost motivation, provide information to parents, and increase students' independence and responsibility. However, research has not been clear on methods to accomplish the many instructional, motivational, and communicative objectives of homework. In fact, the vast majority of research has investigated quantitative variables related to homework tasks. Specifically, time (e.g., "hours of homework assigned by the teacher or spent by the student") appears to be the primary variable of interest in many investigations (Epstein \& Pinkow, 1988).

The relationship between quantitative and qualitative variables in the development, implementation, and effectiveness of homework is not well understood. However, we believe that to maximize the utility of homework as an intervention, greater attention should be paid to qualitative factors. For example, variables related to the (a) quality of homework assignments; (b) teacher, classroom, 
Table 1. Qualitative Variables Related to Homework

I. Homework (Assignment) Variables
A. Clarity of purpose
B. Clarity of instructions
C. Amount of homework assigned
D. Time expected to complete homework
E. Variability in assignments
F. Regularity of assignments
G. Feedback on homework completion

II. School/Teacher/Classroom Variables
A. School policy and standards on homework
B. School history of homework practices
C. Teacher education and experience
D. Teacher philosophy of homework
E. Teacher philosophy and practices of parent involvement
F. Teacher planning time
G. Classroom ecology (e.g., behaviors, interruptions, etc.)

III. Family/Student Variables
A. Parent education
B. Family socioeconomic status indications (e.g., occupation, family size, etc.)
C. Home conditions supporting learning (e.g., place, time, supplies for homework; inter- ruptions and competing responsibilities; resources for learning)
D. Student level of prior achievement
E. Student attitudes about school, homework
F. Student program/track

and school; and (c) family and student, are worthy of investigation. Table 1 presents a number of potential factors within each of these respective areas. This list is by no means exhaustive; interested readers are referred to a report by Epstein and Pinkow (1988), which describes a model for research on homework and offers additional qualitative variables for investigation.

\section{THE ROLE OF THE SCHOOL PSYCHOLOGIST}

School psychologists can adopt various roles in developing, supporting, and monitoring homework programs. Among these roles are assessment, training, and parent-teacher consultation. Specifically, school psychologists can (a) assess homework difficulties; (b) train teachers and parents; and (c) serve as a liaison between home and school.

\section{Assessing Homework Difficulties}

School psychologists have a unique vantage point in schools, which may enhance their ability to conduct an objective assessment prior to implementation of a homework program. The nature and scope of homework problems can be assessed with the Homework Problem Checklist (Anesko et al., 1987). This checklist has been well-researched, and provides information on various potential sources of homework problems. For example, homework problems can be 
classified as organizational (e.g., not knowing what homework to do, or where or when to do it), motivational (e.g., not recognizing the relevance and importance of homework), or informational (e.g., not knowing how to approach homework assignments). The 20 -item checklist is completed by parents. When individual or clusters of items are interpreted, the assessment results can lead directly to appropriate intervention strategies.

Along with assessing specific student difficulties, school psychologists can assess parents' and teachers' needs and abilities to carry out program components. For example, teacher interviews and classroom observations can provide information on current methods of assigning and monitoring homework completion and accuracy. Interviews with parents can uncover conditions at home that may enhance or impede students' accurate completion of homework in that setting. Outcome of the assessment will provide information on parents' and teachers' knowledge or skill deficits that may hinder accurate implementation of homework programs. The school psychologist can then work with the intervention agents directly to develop and reinforce their skills in intervention implementation.

\section{Training Teachers and Parents}

As alluded to earlier, it is possible that the use of multisource, multimethod assessment procedures may indicate the need for direct training of some parents, teachers, and students. Training of parents and teachers is crucial for ensuring that homework is both valued and used appropriately to maximize success of homework as an academic intervention. School psychologists should be aware of differing levels of consumer skill and experience, and focus training efforts on individual needs to maximize program success.

Training of intervention agents (i.e., teachers and parents) can occur in a number of ways. Perhaps the greatest opportunity for a school psychologist to influence organizational practices is through formalized staff development. In-service programs can be implemented to increase the knowledge base of all school staff. For example, several teachers can be involved in group training efforts (e.g., inservices, workshops). Important information that can be shared with teachers include various types of homework (e.g., practice, preparation, extension, creative homework), and characteristics of good homework programs. Table 2 presents information regarding homework that can be shared with teachers in formal training settings.

Several parent training programs have been developed to increase parents' knowledge and skills at promoting effective homework practices at home. These programs are reviewed in an earlier section of this article, and interested readers are referred to the original sources for specific components and procedures. Some of the parent training programs are used with groups of parents in a timelimited fashion (e.g., "Do It Yourself), while others are self-instructional materials (e.g., "Winning the Homework War"). Because parents' abilities to follow through systematically on the various procedures outlined in the programs will 
Table 2. Characteristics of Good Homework Programs

\begin{tabular}{ll}
\hline \multicolumn{1}{c}{ Characteristic } & \multicolumn{1}{c}{ Rationale } \\
\hline $\begin{array}{l}\text { Homework needs to have a clear purpose. Well } \\
\text { planned and systematic assignments produce } \\
\text { more effective learning. }\end{array}$ & $\begin{array}{l}\text { Assignments should be generated by the curric- } \\
\text { ulum. Homework not related to classwork be- } \\
\text { comes "busy" work. }\end{array}$ \\
$\begin{array}{l}\text { Homework assignments should begin with clear } \\
\text { instructions and result in a specific product. }\end{array}$ & $\begin{array}{l}\text { Directions need to be foolproof to eliminate } \\
\text { misunderstandings or incorrect work. Begin as- } \\
\text { signments in class to assure understanding. The } \\
\text { task should contain the element of accountabil- } \\
\text { ity for a specific product. }\end{array}$ \\
$\begin{array}{l}\text { Homework should be completed within a rea- } \\
\text { sonable amount of time with a high (at least }\end{array}$ & $\begin{array}{l}\text { Homework is a task which the student should be } \\
\text { able to complete independently. Some individu- } \\
\text { alization may be necessary. }\end{array}$ \\
$\begin{array}{l}\text { Use variety in the types of assignments given. } \\
\text { Variety is also important across grade level and } \\
\text { subject matter. }\end{array}$ & $\begin{array}{l}\text { Over-reliance on repetitive drill work produces } \\
\text { boredom. A variety of homework assignments } \\
\text { provides children with exposure to a range of } \\
\text { experiences. }\end{array}$ \\
$\begin{array}{l}\text { Homework needs to be assigned regularly. Pa- } \\
\text { rental checking with positive and/or negative } \\
\text { consequences adds to homework's effectiveness. }\end{array}$ & $\begin{array}{l}\text { Regular homework assignments eliminate } \\
\text { guesswork by parents who must supervise home } \\
\text { study. Regularity also promotes building good } \\
\text { study habits. }\end{array}$ \\
$\begin{array}{l}\text { Students need to receive regular feedback and } \\
\text { follow-up. }\end{array}$ & $\begin{array}{l}\text { Regular feedback prevents students from prac- } \\
\text { ticing errors and provides monitoring of skill ac- } \\
\text { quisition. Positive comments are particularly } \\
\text { helpful. }\end{array}$ \\
\hline
\end{tabular}

be variable, it is recommended that school psychologists consider offering group training to parents to ensure that program components are understood and implemented with integrity. Specific training can be provided on a number of dimensions, including the mechanics of setting up homework environments, organizing homework schedules, employing motivational strategies, and encouraging selfmanagement. Likewise, parents can be taught general strategies for talking to their child's teacher about homework problems. For example, parents can elicit information from their child's teacher regarding organizational abilities at school, patterns of work performance in the classroom, specific academic areas that are more and less difficult for their child, and other behavioral concerns.

Along with in-services, workshops, and other group training efforts, school psychologists can train parents and teachers individually or as a pair when serving as a consultant for specific student difficulties. Research on teacher and parent training suggests a number of procedures that are effective in delivering educative services. Didactic instruction, modeling, role playing, cuing, and feedback have all been used effectively by various researchers (Allen \& Forman, 1984; Anderson \& Kratochwill, 1988; Bernstein, 1982; Jones \& Eimers, 1975; Van Houten \& Sullivan, 1975). Findings suggest that didactic instruction should be used in combination with other training methods (e.g., role playing and feedback). In other words, simply providing information is not adequate to change 
behaviors. To increase the effectiveness of parent and teacher training in relation to homework practices, school psychologists should supplement didactic instruction with other procedures such as modeling, role-playing, and performance feedback.

\section{Serving as a Liaison Between Home and School}

Given that homework is assigned at school but compliance is expected at home, an integrated home-school program, including parent and teacher training, seems necessary to secure benefits. Consistency and coordination among parents and teachers is important to increase treatment effectiveness and enhance maintenance and generalization of outcomes. School psychologists are in an ideal position to serve as a liaison between home and school settings, facilitate parentteacher communication, foster coordinated efforts at implementing homework programs, and support and monitor programs.

As a consultant to or liaison between parents and teachers, school psychologists can support effective working relations between parents and teachers, structure programs for home and school, and monitor implementation of homework programs to ensure compliance and follow through. Whereas consultation traditionally has occurred with parents or teachers in an isolated fashion, an integrated consultation approach may be necessary to maximize cross-setting consistency and generalization. Parent-teacher behavioral consultation has been described as a means of joining parents and teachers actively and cooperatively in addressing academic or related concerns of individual students (Sheridan \& Kratochwill, 1992; Sheridan, Kratochwill, \& Elliott, 1990). In this approach, the school psychologist works with parents and teachers together, who serve as joint consultees and share in the identification and remediation of specific homework problems. As such, parents and teachers share the tasks of: (a) identifying the nature of homework problems; (b) developing an effective homework program to be used across home and school settings; (c) monitoring systematically the effects of the intervention on academic and nonacademic skills; (d) determining the need for modification in the homework program; and (e) evaluating overall outcome in relation to its stated objectives.

Given the importance of coordinated efforts among parents, teachers, students, and school psychologists, specific roles and responsibilities of each participant should be clarified. In general, the school psychologist can be responsible for making information about effective programs available to parents and teachers, and for monitoring integrity and effectiveness of the program. It is the teacher's basic responsibility to ensure that homework is assigned in a clear and meaningful way. Students are responsible to see that homework assignments are understood and that the necessary materials are brought home to complete the work in that setting. Finally, parents must have available an appropriate place for homework to be completed, preferably one that is free from distractions and equipped with the necessary supplies.

In sum, school psychologists can serve various functions in a structured, 
home-school homework program. For example, they can assess the nature of homework problems and the needs of students, parents, and teachers. The development and monitoring of a specific home-school program with direct training and on-going consultation are additional important roles for school psychologists. Furthermore, school psychologists may be instrumental in eliciting parental involvement, bridging home and school resources, and establishing effective working relations between parents and teachers to ensure continued partnerships. Of greatest importance is that all parties (i.e., parents, teachers, students, and school psychologists) work together to maximize the inherent benefits of homework as an effective academic intervention.

\section{CONCLUSIONS}

As a whole, the body of research supporting the use of homework to improve academic achievement is formidable. Homework in itself represents a complex teaching and learning strategy. It requires the coordination of parents and teachers to maximize academic gains for students. Both effective teaching practices and parent involvement are essential to provide the appropriate environmental supports and contingencies for successful academic performance.

Teachers and schools have been mandated by national and local policy initiatives to implement homework programs that address skill deficits in core academic subjects. Unfortunately, the promise of behaviorally based academic interventions has been hampered by inadequate or poorly designed programs. The lack of specific parameters and "user friendly" procedures for teachers and parents has limited the utility of homework as an academic intervention. Teachers are particularly sensitive to projects which make increasing demands on teaching time and require clerical work such as grading assignments. Likewise, parents are often uncertain of the most efficacious way to assist in the learning process.

School psychologists can play a critical role in developing and coordinating structured home-school homework programs. However, as with other interventions used in the schools, the components of assessment, training, and consultation must be integrated for the full potential of homework programs to be realized. Given the shared responsibilities between parents, teachers, and students inherent in homework, the school psychologist may be instrumental in establishing mutual involvement, linking home and school resources, and promoting effective and productive work relations. Psychologists, perhaps more than any other school professional, are in a position to access and disseminate relevant research findings to consumers. Furthermore, because of their training in interventions and consultation, school psychologists may be best equipped to coordinate educational programs systematically and with integrity. Finally, analysis and evaluation are additional skills within school psychologists' repertoires that can be incorporated into program implementation. All of these are important roles of school psychology practitioners operating from the standards of best practices within a scientist-practitioner framework. 


\section{References}

Allen, C. R., \& Forman, S. G. (1984). Efficacy of methods of training teachers in behavior modification. School Psychology Review, 13, 26-32.

Anderson, B. (1986). Homework: What do national assessment results tell us. Princeton, NJ: National Assessment of Educational Progress, Educational Testing Service (ERIC Document Reproduction Service No. 276 980).

Anderson, T. K., \& Kratochwill, T. R. (1988). Dissemination of behavioral procedures in the schools: Issues in training. In J. C. Witt, S. N. Elliott, \& F. M. Gresham (Eds.), Handbook of behavior therapy in education (pp. 217-244). New York: Plenum.

Anesko, K. M., \& Levine, F. M. (1987). Winning the homework war. New York: Simon and Schuster.

Anesko, K. M. \& O'Leary, S. G. (1982). Effectiveness of brief parent training for the management of children's homework problems. Child and Family Behavior Therapy, 4 (2), 112-122.

Anesko, K. M., Schoiock, G., Ramirez, R., \& Levine, F. M. (1987). The Homework Problem Checklist: Assessing children's homework difficulties. Behavioral Assessment, 9, 179-185.

Austin, J. D. (1979). Homework research in mathematics. School Science and Mathematics, 79,115-121.

Axelrod, S. (1973). Comparison of individual and group contingencies in two special classes. Behavior Therapy, 4, 83-90.

Bernstein, G. S. (1982). Training behavior change agents: A conceptual review. Behavior Therapy, 13, 1-23.

Bornstein, P. H. \& Quevillon, R. P. (1976). The effects of a self-instructional package on overactive preschool boys. Journal of Applied Behavioral Analysis, 9, 179-188.

Brinks, W. G. (1937). Direct study activities in secondary schools. New York: Doubleday.

Canter, L. \& Hausner, D. (1987). Homework without tears: A parent guide for motivating children to do homework and succeed in school. New York: Harper and Row.

Chadwick, B. A., \& Day, R. C. (1971). Systematic reinforcement: Academic performance of underachieving students. Journal of Applied Behavioral Analysis, 4, 311-319.

Coleman, J. S., Hoffer, T, \& Kilgore, S. (1981). Public and private schools. Washington, DC: U.S. Department of Education.

Cooper, H. (1989). Homework. White Plains, NY: Longman, Inc.

Crouch, P. L., Gresham, F. M., \& Wright, W. R. (1985). Interdependent and independent group contingencies with immediate and delayed reinforcement for controlling classroom behavior. Journal of School Psychology, 23, 177-187.

Dangel, R. F., \& Polster, R. A. (1984). Parent training. New York: Guilford.

Dougherty, E. H., \& Dougherty, A. (1977). The daily report card: A simplified and flexible package for classroom behavior management. Psychology in the Schools, 14, 191-195.

Elliott, S. N., \& Shapiro, E. S. (1990). Intervention techniques and programs for academic performance problems. In T. B. Gutkin \& C. R. Reynolds, (Eds.), Handbook of school psychology (2nd ed., pp. 635-660). New York: Wiley.

Epstein, J. L. (1988a). Homework practices, achievements, and behaviors of elementary school students. Baltimore, MD: Johns Hopkins University, Center for Research on Elementary and Middle Schools (Report No. 26).

Epstein, J. L. (1988b). A model for research on homework based on U.S. and international studies. Baltimore, MD: Johns Hopkins University, Center for Research on Elementary and Middle Schools (Report No. 27).

Epstein, J. L., Jackson, V. E., \& Salinas, K. C. (1992). Manual for teachers: Teachers Involve Parents in Schoolwork (TIPS) language arts and science/health interactive homework in the middle grades. Center on Families, Communities, Schools, and Children's Learning. Baltimore, MD: Johns Hopkins University.

Epstein, J. L., \& Pinkow, L. (1988). A model for research on homework based on U. S. and international studies. Baltimore, MD: Johns Hopkins University, Center for Research on Elementary and Middle Schools (Grant No. OERI-G-86-90006, Report No. 27).

Epstein, J. L., \& Salinas, K. C. (1991). Teachers Involve Parents in Schoolwork (TIPS): Social stud- 
ies and art manual. Baltimore, MD: Johns Hopkins University, Center on Families, Communities, Schools, and Children's Learning.

Epstein, J. L., \& Salinas, K. C. (1992). Manual for teachers: Teachers Involve Parents in Schoolwork (TIPS) math and science interactive homework in the elementary grades. Baltimore, MD: Johns Hopkins University, Center on Families, Communities, Schools, and Children's Learning.

Fantuzzo, J. W., Rohrbeck, C. A., \& Azar, S. T. (1986). A component analysis of behavioral self-management interventions with elementary school students. Child and Family Behavior Therapy, 9, 33-43.

Fish, M. C, \& Mendola, L. R. (1986). The effect of self-instruction training on homework completion in an elementary special education class. School Psychology Review, 15, 268-276.

Foyle, H. C. (1984). The effects of preparation and practice homework on student achievement in tenth grade American History. (Doctoral dissertation, Kansas State University, 1984). Dissertation Abstracts International, 45, 2474a-2475a.

Foyle, H. C, \& Bailey, G. D. (1988). Research homework experiments in social studies: Implications for teaching. Social Education, 52, 292-298.

Fredrick, W C, \& Walberg, H. J. (1980). Learning as a function of time. Journal of Educational Research, 73, 183-194.

Friesen, C. D. (1979). The results of homework versus no-homework research studies. Iowa City, IA: University of Iowa. (ERIC Document Reproduction Service No. ED 167 508.)

Goldstein, A. (1960). Does homework help? A review of research. Elementary School Journal, 60, 212-224.

Harding, R. C. (1979). The relationship of teacher attitudes towards homework and academic achievement of primary grade students. Unpublished doctoral dissertation, Lehigh University, Philadelphia, PA.

Harris, V. W, \& Sherman, J. A. (1974). Homework assignments, consequences, and class performance in social studies and mathematics. Journal of Applied Behavior Analysis, 7, 505-519.

Hart, D., \& Rechif, M. (1986). Mind movers: Creative homework assignments grades 3-6. Reading, MA: Addison-Wesley.

Holman, J., \& Baer, D. M. (1979). Facilitating generalization of on-task behavior through self-monitoring of academic tasks. Journal of Autism and Development Disabilities, 9, 429-446.

Homer, C. M. (1987). Homework: A way to teach problem solving. Academic Therapy, 22, 239-244.

Johnson, D. W., \& Johnson, R. T. (1985). The internal dynamics of cooperative learning groups. In R. Slavin, S. Sharan, S. Kagan, R. H. Lazarowitz, C. Webb, \& R. Schmuck (Eds.), Learning to cooperate, cooperating to learn (pp. 103-124). New York: Plenum.

Johnston, R. J., \& McLaughlin, T. F. (1982). The effects of free time on assignment completion and accuracy in arithmetic: A case study. Education and Treatment of Children, 5, 33-40.

Joint Commission on Mental Health of Children. (1970). Crisis in child mental health: Crisis for the 1970 's. New York: Harper and Row.

Jones, F. H., \& Eimers, R. C. (1975). Role playing to train elementary teachers to use a classroom management "skill package." Journal of Applied Behavioral Analysis, 8, 421-433.

Karoly, P., \& Kanfer, F. H. (Eds.) (1982). Self-management and behavior change: From theory to practice. Elmsford, NY: Pergamon.

Kazdin, A. E. (1975). Behavior modification in applied settings. Homewood, IL: Dorsey Press.

Keith, T. Z. (1982). Time spent on homework: A large sample path analysis. Journal of Educational Research, 74, 248-253.

Keith, T. Z. (1986). Homework. Kappa Delta Phi Classroom Practice Series. West Lafayette, IN: Kappa Delta Phi.

Keith, T. Z. (1987). Children and homework. In A. Thomas \& J. Grimes (Eds.), Children's needs: Psychological perspectives (pp. 275-282). Washington, DC: NASP Publications.

Kelley, M. L. (1990). School home notes: Promoting children's classroom success. New York: Guilford.

Knorr, C. L. (1981). A synthesis of homework research and related literature. Bethlehem, PA: Paper presented to Lehigh Chapter of Phi Delta Kappa (ERIC Document Reproduction Service No. ED199 933). 
Kuepper, J. E. (1987). Homework helpers: A guide for parents offering assistance. Minneapolis, MN: Educational Media.

Kuhlman, C. E. (1973). The effects of training parents in behavior modification procedures for child management on the child's academic behavior, achievement and attitudes and on the parent's and the child's perception of the parent-child relationship. Unpublished doctoral dissertation, University of Colorado, Denver, CO.

LaConte, R. T. (1981). Homework as a learning experience: What research says to the teacher. (Report No. 1036-1-10). West Haven, CT: National Education Association, NEA Professional Library.

Lee, J. F., \& Pruitt, K. W. (1979). Homework assignments: Classroom games or teaching tools. Clearing House, 53, 31-35.

Lieberman, L. (1983). The homework solution. Journal of Learning Disabilities, 16, 435.

Litlow, L., \& Pumroy, D. K. (1975). A brief review of classroom group-oriented contingencies. Journal of Applied Behavior Analysis, 8, 341-347.

Lordeman, A. M., \& Winett, R. A. (1980). The effects of written feedback to parents and a call-in service on student homework submission. Education and Treatment of Children, 3, 33-44.

Maertens, D., \& Johnson, K. (1972). Effects of arithmetic homework upon the attitudes and achievement of 5th and 6th grade pupils. School Science and Mathematics, 72, 117-126.

Malyn, D. (1985). Use of chart moves and spinners with homework compliance. Unpublished masters thesis, University of Utah, Salt Lake City, UT.

Marshall, P. M. (1983). Homework and social facilitation theory in teaching elementary school mathematics. Unpublished doctoral dissertation, Stanford University, Stanford, CA.

Meichenbaum, D., \& Goodman, J. (1971). Training impulsive children to talk to themselves: A means of developing self control. Journal of Abnormal Psychology, 77, 115-126.

Miller, D. L., \& Kelley, M. L. (1991). Interventions for improving homework performance: A critical review. School Psychology Quarterly, 6, 174-185.

Nastasi, B. K., \& Clements, D. H. (1991). Research on cooperative learning: Implications for practice. School Psychology Review, 20, 110-131.

National Commission on Excellence in Education. (1983). A nation at risk: The imperative for educational reform. Washington, DC: U.S. Department of Education.

Olympia, D. E., Andrews, D., Valum, J. L., \& Jenson, W. R. (1991). Do it together: A team approach to homework. (Available from W Jenson, $327 \mathrm{MBH}$, University of Utah, Salt Lake City, UT 84112.)

Olympia, D. E., Jenson, W R., \& Neville, M. R. (1990). Do it yourself homework manual: A sanity saver for parents. (Available from W Jenson, 327 MBH, University of Utah, Salt Lake City, UT 84112.)

Olympia, D. E., Jenson, W. R., \& Sheridan, S. M. (1992, March). Team homework: A student-managed program to improve homework compliance and accuracy. Paper presented at the annual meeting of the National Association of School Psychologists, Nashville, TN.

Otto, W. (1985). Homework: A meta-analysis. Journal of Reading Research, 5, 764-766.

Paschal, R. A., Weinstein, T, \& Walberg, H. J. (1984). The effects of homework on learning: A quantitative synthesis. Journal of Educational Research, 78, 97-104.

Phillips, E. L. (1968). Achievement place: Token reinforcement procedures in a home-style rehabilitation setting for predelinquent boys. Journal of Applied Behavior Analysis, 1, 213-223.

Pigott, E. , Fantuzzo, J. W, Heggie, D. L., \& Clement, P. W. (1984). A student-administered grouporiented contingency intervention: Its efficacy in the classroom. Child and Family Behavior Therapy, 6, 41-55.

Polachek, S. W, Kniesner, T. J., \& Harwood, H. J. (1978). Educational production functions. Educational Researcher, 10, 7-17.

Roberts, R. N., \& Dick, M. L. (1982). Self control in the classroom: Theoretical issues and practical applications. In T. R. Kratochwill (Ed.) Advances in school psychology (Vol. 2) (pp. 275-314). Hillsdale, NJ: Lawrence Erlbaum.

Rousseau, M. A., Poulson, C. L., \& Salzberg, C. L. (1984). Naturalistic procedures for homework participation by inner-city middle school students. Education and Treatment of Children, 7, 1-15. 
Rutherford, R. B., \& Nelson, C. M. (1988). Generalization and maintenance of treatment effects. In J.C. Witt, S. N. Elliott, \& F. M. Gresham (Eds.), Handbook of behavior therapy in education (pp. 277-324). New York: Plenum.

Rutter, M., Maughn, B., Mortimore, P., Ouston, J., \& Smith, A. (1979). Fifteen thousand hours: Secondary schools and their effects on children. Cambridge, MA: Harvard University Press.

Shapiro, E. S. (1986). Behavior modification: Self-control and cognitive procedures. In R. P. Barrett(Ed.), Severe behavior disorders in the mentally retarded (pp. 61-97). New York: Plenum.

Sharan, S. (1980). Cooperative learning in small groups: Recent methods and effects on achievement, attitudes and ethnic relations. Review of Educational Research, 50, 241-271.

Sheridan, S. M., \& Kratochwill, T. R. (1992). Behavioral parent-teacher consultation: Conceptual and research considerations. Journal of School Psychology, 30, 117-139.

Sheridan, S. M., Kratochwill, T. R., \& Elliott, S. N. (1990). Behavioral consultation with parents and teachers: Delivering treatment for socially withdrawn children. School Psychology Review, 19, 33-52.

Shores, R. E., Appoloni, T, \& Norman, C. (1976). Changes in peer verbalization accompanying individual and group contingencies to modify on-task behavior. Perceptual and Motor Skills, 43, $1155-1162$.

Slavin, R. E. (1985). An introduction to cooperative learning research. In R. Slavin, S. Sharan, S. Kagan, R. H. Lazarowitz, C. Webb, \& R. Schmuck (Eds.), Learning to cooperate, cooperating to learn (pp. 5-15). New York: Plenum.

Slavin, R. E. (1983). Cooperative learning. New York: Longman.

Slavin, R. E. (1980). Cooperative learning. Review of Educational Research, 50, 315-342.

Smith, D. J., Young, K. R., Nelson, J. R., \& West, R. P. (1992). The effect of a self-management procedure on the classroom and academic behavior of students with mild handicaps. School Psychology Review, 21, 59-72.

Strang, R. M. (1968). Guided study and homework. What research says to the teacher. Washington, DC: National Education Association.

Strang, R. M. (1975). Guided study and homework. What research says to the teacher. Washington, DC: National Education Association.

Stokes, T. F., \& Baer, D. M. (1977). An implicit technology of generalization. Journal of Applied Behavior Analysis, 10, 349-368.

Stokes, T. F., \& Osnes, P. G. (1986). Programming the generalization of children's social behavior. In P. S. Strain, M. J. Guralnick \& H. Walker (Eds.), Children's social behavior: Development, assessment and modification (pp. 407-443). Orlando: Academic.

Tavormina, J. B. (1980). Evaluation and comparative studies of parent education. In R. R. Abidin (Ed.), Parent education and intervention handbook (pp. 130-155). Springfield, IL: Thomas.

Van Houten, R., Hill, S., \& Parsons, M. (1975). An analysis of the performance feedback system: The effects of timing and feedback, public posting, and praise upon academic performance and peer interaction. Journal of Applied Behavior Analysis, 8, 449-447.

Van Houten, R., \& Lai Fatt, D. (1981). The effects of public posting on high school biology test performance. Education and Treatment of Children, 4, 217-226.

Van Houten, R., \& Sullivan, K. (1975). Effects of an audio cueing system on the rate of teacher praise. Journal of Applied Behavior Analysis, 8, 197-202.

Van Houten, R., \& Thompson, C. (1976). The effects of explicit timing on math performance. Journal of Applied Behavior Analysis, 9, 227-230.

Walberg, H. J., Paschal, R. A., \& Weinstein, T. (1985). Homework's powerful effects on learning. Educational Leadership, 42, 76-79.

Wolfe, J. A., Fantuzzo, J., \& Wolter, C. (1984). Student-administered group-oriented contingencies: A method of combining group-oriented contingencies and self-directed behavior to increase academic productivity. Child and Family Behavior Therapy, 6, 45-59. 